\title{
Hypoglycin Stimulates Insulin Secretion
}

\author{
R. D. G. Milner and P. K. Wirdnam \\ Department of Paediatrics, University of Sheffield, Children's Hospital Sheffield, England
}

\begin{abstract}
Summary. Hypoglycin A (0.01-1.0 mmol/1) stimulated insulin release from pieces of rabbit pancreas in vitro in the presence or absence of extracellular glucose. The relevance of this finding to the hypoglycaemia of Jamaican vomiting sickness is discussed.
\end{abstract}

Key words: Hypoglycin, insulin secretion, rabbit pancreas, glucose, radioimmunoassay.

Methylenecyclopropyl alanine, known commonly as hypoglycin $A$, is found in the unripe fruit of the ackee tree (Blighia sapida) and there is now good evidence that hypoglycin $A$ is the toxin responsible for Jamaican vomiting sickness $[1,2]$. In the illness, which most commonly affects undernourished children during the winter months, there is an acute onset of vomiting coupled with change in the level of consciousness which may rapidly progress to coma and death. The biochemical abnormality most characteristic of the patient is hypoglycaemia [3]. A comprehensive explanation of the mechanism by which hypoglycin and related compounds cause hypoglycaemia has been offered by Senior, Holland and Sherratt [4]. In this, hypoglycin and its metabolites inhibit fatty acid and ketone body oxidation so that glucose becomes the main energy substrate. Since gluconeogenesis is also impaired hypoglycaemia is the consequence of the exhaustion of glucose reserves. Hormonal changes are not thought to play a significant part in the hypoglycaemia but no direct measurement of plasma insulin levels in clinical cases or study of the effect of hypoglycin on insulin secretion has been reported. This is surprising because hypoglycin and leucine are structurally similar [5] and leucine is recognised as an insulin secretogogue [6]. We have therefore studied the effect of hypoglycin on insulin release from pieces of rabbit pancreas incubated in vitro.

\section{Materials and Methods}

The experimental design was as described previously [6]. In one experiment 10 to 12 pieces of pancreas from one rabbit were used. Each piece was incubated separately for consecutive periods of 90,30 and $30 \mathrm{~min}$. An equal number of pieces were incubated in glucose free medium and in medium containing $16.5 \mathrm{mmol} / \mathrm{l}$ glucose. No measurement of insulin release was made in the initial 90 min incubation. Insulin release $\left(\mu \mathrm{U} / \mathrm{mg} 30 \mathrm{~min}^{-1}\right)$ was measured in the first 30 min incubation which was the control for the second $30 \mathrm{~min}$ incubation in which hypoglycin (kindly given by Dr.H.S.A. Sherratt) was added to the medium. Hypoglycin was employed in a range of logarithmically increasing doses from 0.01 to $1.0 \mathrm{mmol} / 1$. Each experiment was repeated two or three times and the combined mean rate of insulin secretion in control and test incubations was compared using Student's $t$ test for paired observations.

\section{Results and Discussion}

Earlier work [7] has demonstrated the need for a prolonged initial incubation before measuring insulin release from pieces of rabbit pancreas incubated in vitro. If the initial incubation is 60 or 90 min, insulin release in glucose free or glucose enriched medium is usually stable for up to a further three hours. If drift occurs under constant incuba- 
Table 1. Mean $\left( \pm\right.$ SEM) insulin release $\left(\mu \mathrm{U} / \mathrm{mg} 30 \mathrm{~min}^{-1}\right)$ from pieces of rabbit pancreas incubated in medium containing $16.5 \mathrm{mmol} / 1$ glucose or no glucose and different concentrations of hypoglycin

\begin{tabular}{|c|c|c|c|c|c|}
\hline \multirow{2}{*}{$\begin{array}{l}\text { Hypoglycin concentration } \\
(\mathrm{mmol} / \mathrm{l})\end{array}$} & \multirow{2}{*}{$\begin{array}{l}\text { Glucose concentration } \\
(\mathrm{mmol} / \mathrm{l})\end{array}$} & \multirow{2}{*}{$\begin{array}{l}\text { No. of } \\
\text { observations }\end{array}$} & \multicolumn{3}{|c|}{ Insulin release $\left(\mu \mathrm{U} / \mathrm{mg} 30 \mathrm{~min}^{-1}\right)$} \\
\hline & & & $\begin{array}{l}\text { Control } \\
90-120 \mathrm{~min}\end{array}$ & $\begin{array}{l}\text { Test } \\
120-150 \mathrm{~min}\end{array}$ & Change \\
\hline \multirow[t]{2}{*}{0.01} & 0 & 13 & $3.75 \pm 1.13$ & $8.53 \pm 1.83$ & $+4.78 \pm 1.81^{*}$ \\
\hline & 16.5 & 15 & $16.48 \pm 1.90$ & $20.62 \pm 2.04$ & $+4.14 \pm 1.72^{*}$ \\
\hline \multirow{2}{*}{0.0316} & 0 & 10 & $2.81 \pm 0.71$ & $2.94 \pm 0.69$ & $+0.09 \pm 0.68$ \\
\hline & 16.5 & 16 & $25.48 \pm 5.72$ & $27.65 \pm 6.20$ & $+2.17 \pm 1.89$ \\
\hline \multirow[t]{2}{*}{0.1} & 0 & 14 & $2.41 \pm 0.61$ & $6.63 \pm 1.36$ & $+4.2 \pm 0.94^{* *}$ \\
\hline & 16.5 & 15 & $12.27 \pm 3.83$ & $20.59 \pm 2.73$ & $+8.32 \pm 2.7^{* *}$ \\
\hline \multirow[t]{2}{*}{0.316} & 0 & 15 & $295 \pm 0.53$ & $9.30 \pm 1.84$ & $+6.35 \pm 1.88^{* *}$ \\
\hline & 16.5 & 16 & $30.04 \pm 5.38$ & $42.19 \pm 5.59$ & $+12.59 \pm 5.01^{*}$ \\
\hline \multirow[t]{2}{*}{1.0} & 0 & 14 & $1.76 \pm 0.66$ & $355 \pm 1.07$ & $+1.79 \pm 0.68^{*}$ \\
\hline & 16.5 & 15 & $9.00 \pm 2.30$ & $11.72 \pm 2.70$ & $+2.72 \pm 0.71 * *$ \\
\hline
\end{tabular}

Level of significance: $* \mathrm{P}<0.05, * * \mathrm{P}<0.01$

tion conditions there is a gradual decline of insulin secretion with time. The experimental design is therefore appropriate for the study of a potential stimulator of insulin secretion. Each experiment was repeated two or three times to avoid the risk of artefact from small group bias. The variation between insulin release from different pancreases is well known and is reflected in the differences between the mean rates of insulin release in $16.5 \mathrm{mmol} / \mathrm{lglu}$ cose in control periods and in the high standard errors. The problem is offset by using each piece as its own control.

Hypoglycin stimulated insulin release from rabbit pancreas in vitro consistently at concentrations of $0.01,0.1,0.316$ and $1.0 \mathrm{mmol} / 1$ in the presence or absence of glucose (Table 1). No explanation can be offered for the failure of hypoglycin to stimulate insulin release at the concentration of $0.0316 \mathrm{mmol} / \mathrm{l}$. A wide range of hypoglycin concentrations was chosen for two reasons. We wished to extend the dilutions to a level that might occur in vivo though this was a speculative exercise since there is no record of circulating hypoglycin concentrations in clinically ill patients or experimental animals. Second it was possible that hypoglycin might have a dual action on the $\beta$ cell in acting as an insulin secretogogue but also interfering with the intermediary metabolism of the cell. In this context it is noteworthy that the $1.0 \mathrm{mmol} / \mathrm{l}$ hypoglycin caused a smaller stimulation of insulin release than 0.1 or $0.316 \mathrm{mmol} / 1$.

The results of these experiments suggest that the mechanism by which hypoglycin causes hypoglycaemia may be more diverse than has been hitherto appreciated. The evidence for the major effect of hypoglycin being inhibition of fatty acid oxidation and gluconeogenesis is compelling and it is not surprising that hyperinsulinaemia has been discounted as playing a part in hypoglycin intoxication
[4]. But the assertion has been made without evidence and this study has shown that the $\beta$ cell responds to hypoglycin, possibly as an analogue of leucine, with increased insulin release. The demonstration that hypoglycin acts in a glucose free medium is an empirical similarity to leucine which is the only essential amino acid with this property [6]. It will be of interest if a similar effect can be demonstrated in vivo clinically or experimentally.

\section{References}

1. Bressler, R., Corredor, C., Brendel, K.: Hypoglycin and hypoglycin-like compounds. Pharmacol. Rev. 21, 105-130 (1969)

2. Tanaka, K., Kean, E.A., Johnson, B.: Jamaican Vomiting Sickness. biochemical investigation of two cases. N. Engl. J. Med. 295, 461-467 (1976)

3. Jelliffe, D. B., Stuart, K L.: Acute toxic hypoglycaemia in the vomiting sickness of Jamaica. Br. Med. J. 1954 I, 75-77

4 Senior, A.E, Holland, P.C., Sherratt, H. S. A.: Mechanism of the hypoglycemic effects of hypoglycin and pent-4-enoic acid. In: E.A. Kean (ed.): Hypoglycin, pp. 109-119. London: Academic Press 1976

5 Fowden, L.: Possible roles of hypoglycin as an amino acid analogue In: E. A. Kean (ed.); Hypoglycin, pp. 175-181. London. Academic Press 1976

6. Milner, R.D.G.. The stimulation of insulin release by essential amino acids from rabbit pancreas in vitro $\mathrm{J}$ Endocrinol. 47, 347-356 (1970)

7. Milner, R.D.G : Some studies on the development of the islets of Langerhans. University of London: M.D. Thesis 1968

Received May 25, 1977, and in revised form: July 29, 1977

Prof. R. D G. Milner

Department of Paediatrics

Children's Hospital

Sheffield, S10 2TH

England 